median age; $70.8 \pm 7.9$ years), and were allocated to a CPM group ( $\mathrm{n}=31$, with median age; $69.7 \pm 8.4$ years). Patients were evaluated regarding knee function score (Hospital for Special Surgery (HSS) score), pain (Numeric Pain Rating Scale (NPRS)), knee circumference, knee range of motion, length of hospital stay, the day of knee flexion angle achieved 70 degrees and quality of life (Short-Form 12 Health Survey (SF-12). Functional activities were evaluated using the lowa Level of Assistance Scale and walking speed was evaluated using the lowa Ambulation Velocity Scale. Also functional outcomes were evaluated with timed up and go (TUG) test and 10-meter walk test (10 MWT). Patients were evaluated preoperatively and at discharge.

Results: At baseline, demographic and anthropometric characteristics were similar in groups and there was no statistically difference between groups $(p>0.05)$. It was determined that; the AROM group had better results in terms of reduction of pain severity $(p<0.001)$. When the HSS knee scores were compared there was statistically difference between groups $(p<0.001)$ and the HSS knee scores were lower in CPM group after surgery. There were no statistical differences in knee circumference, knee range of motion, the day of achieved active straight leg raise, length of hospital stay, the day of knee flexion angle achieved 70 degrees, quality of life, the IOWA help level score, IOWA walking speed score, 10 MWT score and TUG test score between groups after TKR $(p>0.05)$.

Conclusions: In patients with TKR, application of repetitive AROM has better results than CPM to decrease pain severity, improve the HSS knee score. However, AROM has no effect on the early functional outcomes and the other early patients' outcomes. The current results suggest that application of AROM might be an effective method to decrease pain severity, improve the HSS knee score.

References:

[1] Maniar RN, Baviskar JV, Singhi T, et al. To use or not to use continuous passive motion post-total knee arthroplasty: Presenting functional assessment results in early recovery. The Journal of Arthroplasty. 2012;27(2),193-200.

[2] Bruun-Olsen V, Heiberg KE, Mengshoel AM. Continuous passive motion as an adjunct to active exercises in early rehabilitation following total knee arthroplasty-a randomized controlled trial. Disability and Rehabilitation. 2009;31(4), 277-283.

Disclosure of Interest: None declared

DOI: 10.1136/annrheumdis-2017-eular.5851

\section{AB0807 VALIDITY OF THE QUADRICEPS ANGLE MEASUREMENT IN PATIENTS WITH VARUS KNEE OSTEOARTHRITIS: COMPARE THE GONIOMETRIC AND PHOTOGRAMMETRY METHOD TO RADIOGRAPHY METHOD}

M. Erduran ${ }^{1}$, M. Eymir ${ }^{2}$, B. Ünver ${ }^{2}$, N.D. Demirkıran ${ }^{3} \cdot{ }^{1}$ Faculty of Medicine Surgery Medicine Department of Orthopaedics and Traumatology, Dokuz Eylül University, Izmir, Turkey; ${ }^{2}$ School of Physical Therapy and Rehabilitation, Dokuz Eylül University, Izmir, Turkey; ${ }^{3}$ Department of Orthopaedics and Traumatology, Dokuz Eylül University, Izmir, Turkey, Izmir, Turkey

Background: Various measurement methods have been defined to assess the alignment of the lower extremities. The $\mathrm{Q}$-angle measurement is reported to be associated with knee injury and patellofemoral dysfunction. The Q-angle has been assessed using radiography scans, goniometer and photogrammetry methods in supine and standing positions. The radiography method is accepted to be the most accurate and valid measurement technique in measurement the $\mathrm{Q}$-angle. But as a result of being expensive and time-consuming, this invasive method is not mostly preferred in research and clinics. The goniometric measurement of $\mathrm{Q}$-angle is practical because it is simple, requires inexpensive equipment (only a goniometer), and can be applied in a short time. Photogrammetry measurement technique is also an advantageous method for reducing measurement errors caused by goniometers and reduction of investigator errors.

Objectives: The aim of the present study, was to compare the clinical assessment of the Q-angle (goniometric and photogrammetric measurement methods) to a radiological assessment using radiograph (criterion validity) in patients with varus knee osteoarthritis.

Methods: The study group consisted of 15 (median age $68.6 \pm 11.9$ years) patients with unilateral and bilateral varus knee osteoarthritis. Q-angle measurements were assessed on both lower extremities with three different goniometric methods (goniometric measurement method in standing position with quadriceps muscle relaxed; goniometric measurement method in supine position with quadriceps muscle relaxed; and contracted) using a $360^{\circ}$ universal goniometer. After the goniometric measurements, photographs were taken with quadriceps muscle relaxed in standing position. For radiographic assessment, we used patients' lower extremity scanograms, which had been taken to determine the diagnosis and treatment from the Computer Patient Archiving System database.

Results: There was a good correlation between the radiographic assessment and photogrammetric measurement $(r=0.623, p<0.001)$. Also a good correlation was observed between radiographic assessment and goniometric measurement (in standing position with quadriceps muscle relaxed; in supine position with quadriceps muscle relaxed; and contracted) $(r=0.676, p<0.001, r=0.616, p<0.001$, $r=0.676, p<0.001$, respectively).

Conclusions: According to our result, the photogrammetric measurement and the goniometric measurement appear to be valid alternatives to the radiographic measurement for determining the $\mathrm{Q}$-angle. These alternative measures might be used by clinicians and researchers to measure the Q-angle of patients with varus knee osteoarthritis in orthopaedic clinics.

Disclosure of Interest: None declared

DOI: 10.1136/annrheumdis-2017-eular.6827

\section{AB0808 COMPARING THE EFFECTS OF PHYSICAL THERAPY AND NON-STEROIDAL ANTI-INFLAMMATORY TREATMENT ON SLEEP QUALITY, QUALITY OF LIFE AND CLINICAL STATUS IN KNEE OSTEOARTHRITIS}

M. Sezgin ${ }^{1,1}$, E. Yeşildal ${ }^{1}$, H. Ankaralı ${ }^{2}$, G. Sahin ${ }^{1} .{ }^{1}$ Department of Physical Medicine and Rehabilitation, Mersin University Medical Faculty, Mersin;

${ }^{2}$ Department of Biostatistics and Medical Informatics, Duzce University Medical Faculty, Düzce, Turkey

Objectives: We aimed to compare the effectiveness of physical therapy (PT) and non-steroidal anti-inflammatory drug (NSAID) therapy on sleep quality, quality of life and clinical status in patients with knee osteoarthritis (OA).

Methods: Demographic characteristics of the participants were recorded. MOS sleep scale, Nottingham Health Profile (NHP) and Western Ontario ve McMaster Universities Osteoarthritis Index (WOMAC) were used to evaluate sleep quality, quality of life and clinical status of patients before and after the treatment.All patients were divided into two groups as PT (57 patients) and NSAID (43) groups. The patients in the drug group were administered oral dexketoprofen $(50 \mathrm{mg} /$ day, for two week) and the patients in the PT group were administered five times a week, total 15 seances hot-pack, ultrasound and transcutaneous electrical nerve stimulation therapy.

Results: Demographic characteristics, MOS sleep scale and NHP were similar at baseline in both groups $(p>0.05)$. WOMAC pain, stiffness, and physical function scores before treatment were significantly poorer in the PT group than the NSAID group $(P<0.05)$. There were statistically significant improvements on the MOS sleep scale (except snoring subscore, $p=0.05$, table 1 ), NHP (except social isolation, $p=0.209$ ) and and WOMAC pain, stiffness, physical function and total scores of both groups after the treatments $(p<0.05)$. Improvement was also similar when both groups were compared after the treatment $(p>0.05)$. After the two treatment, significantly side effect was not observed.

Conclusions: PT and NSAID therapy has good effectiveness on sleep quality, quality of life and clinical status in knee OA.

References:

[1] Wilcox S, Brenes GA, Levine D, et al. Factors related to sleep disturbance in older adults experiencing knee pain or knee pain with radiographic evidence of knee osteoarthritis. J Am Geriatr Soc 2000; 48:1241.

[2] Vivien CA, Priscilla SA, Christian G. Sleep and rheumatologic disorders. Sleep medicine reviews 2008;12: 211-228.

[3] Dieppe PA, Lohmander LS. Pathogenesis and management of pain in osteoarthritis. Lancet 2005; 365:965-973.54.

[4] Fielden JM, Gander PH, Horne JG, et al. An assessment of sleep disturbance in patients before and after total hip arthroplasty. J Arthroplasty 2003; 18:371-6.

[5] Hunter DJ, Lo GH. The management of osteoarthritis: an overwiev and call to appropriate conservative treatment. Rheum Dis Clin N Am 2008; 34:689-712.99.

[6] Hays RD, Martin SA, Sesti AM, Spritzer KL. Psychometric properties of the Medical Outcomes Study Sleep measure. Sleep Med 2005; 6:41-44.

Disclosure of Interest: None declared

DOI: 10.1136/annrheumdis-2017-eular.3910

\section{AB0809 FALL RISK AND RELATED FACTORS IN KNEE OSTEOARTHRITIS}

M. Alkan Melikoglu ${ }^{1}$, A. Kul ${ }^{2} .{ }^{1}$ Rheumatology; ${ }^{2}$ Physical Medicine and Rehabilitation, Ataturk University Faculty of Medicine, Erzurum, Turkey

Background: Balance, as a complex task, may be affected in knee osteoarthritis $(\mathrm{KOA})$ and this may cause postural instability and fall risk.

Objectives: The aim of this study was to determine the fall risk in patients with KOA with an objective computerized technique and to evaluate the potential risk factors for falls in these patients.

Methods: Patients with KOA and controls were included in this cross-sectional study. Gender, age, and body mass index (BMI) were recorded. Pain was evaluated with a visual analog scale (VAS). The Western Ontario and McMaster Universities Osteoarthritis Index (WOMAC) was used to assess the patients and the Falls Efficacy Scale International (FES-I) was used for the evaluation of fall efficacy. Knee radiographs were recorded with the Kellgren-Lawrence grading scale. Fall risk analysis was performed by using the Tetrax Interactive Balance System, which is a computerized posturography device.

Results: One hundred patients with KOA and 30 controls were included. The age, gender, and BMI scores were similar between the groups. FES-I scores were significantly higher in the cases than in the controls $(p<0.000)$. Using a computerized system, significantly higher fall risk results $(p<0.000)$ and significantly low, moderate, and high fall risk distribution were recorded in the cases than in the controls $(p<0.000)$. Fall risk was significantly related to age, pain, and the WOMAC scores of the patients. 